\title{
A CRUZADA CONTRA AS TREVAS: ENSAIO SOBRE O ESFORÇO HUMANO PARA ILUMINAR SEUS ESPAÇOS DE CONVIVÊNCIA
}

Orestes Jayme Mega ${ }^{1}$

\section{RESUMO}

O esforço humano para iluminar seus espaços de convivência gerou uma série de artefatos relacionados à iluminação que não tem sido muito explorada pela arqueologia. Este ensaio propõe uma abordagem arqueológica da luz como representando não apenas um recurso natural, mas também um elemento carregado de miticidade que pode ter sido usado em cerimônias religiosas desde o paleolítico. A principal intenção deste ensaio é explorar as possibilidades teóricas de uma "arqueologia da luz", enfocando seus aspectos míticoideológicos.

Palavras-chave: luz, mitologia; Arqueologia; antropoceno; teoria

\section{ABSTRACT}

The human effort to enlighten its spaces of convivence generated a series of artifacts related to enlightenment that has been not explored very well by the archaeology. This essay purposes an archaeological approach of the light as representing not only a natural resource, but a element full of a mythical purposes that can be used in religious ceremonies since the paleolithic. The main intention of this essay is to explore the theoretical possibilities of a "archaeology of the light", focusing in its mythical-ideological aspects.

Keywords: light; mithology; Archaelogy; anthropocene; theory

\section{RESUMEN}

El esfuerzo humano para iluminar sus espacios de convivencia generó una serie de artefactos relacionados a la iluminación que no tiene sido mucho explorada por la arqueologia. Este ensaio tiene como propuesta una aborgage arqueológica de la luz como representando no solamante un recurso natural, pero también un elemento cargado de miticidad que puede tener sido usado en cerimonias religiosas desde el paleolítico. La principal intención deste ensaio es explorar las possibilidades teóricas de una "arqueologia de la luz", enfocando sus aspectos mítico-ideológicos.

Palabras clave: luz, mitologia; Arqueología; antropoceno; teoria

\section{Introdução}

1 Bacharel em Arqueologia e Preservação Patrimonial pela Univasf e Mestrando em Antropologia pela Ufpel. Endereço: rua João Bortolotto, 240, centro. Município de Ipê, RS. Tel. (54) 96208133. Email: orestes mega@yahoo.com.br. Orcid: http//orcid.org/0000-0003-0749-1829. 


\section{Revista de Arqueologia Pública}

E disse Deus: haja luz, e a luz se fez (Gênesis, capítulo 1, versículo 3). Assim prossegue o relato mítico da criação do universo logo após Deus ter criado o céu e a terra. Antes da criação da luz, havia apenas uma caótica uniformidade na densidão das trevas originais. A criação da luz, de acordo com a mitologia judaico-cristã, é o evento que dá origem a todos os demais eventos que visam dar uma ordem ao caos original. Pode-se dizer que a criação da luz é o evento mítico que vivifica e ordena o cosmos. A luz inaugura o universo e torna-o possível de ser habitado pelos seres humanos. No Popol Vuh, livro sagrado do povo Maia, no princípio, tudo estava envolto em silêncio e obscuridade (III, 11). As divindades que construiriam o mundo viviam imersos numa luz difusa que as iluminava (IV, 12). A criação da luz tal como a humanidade a conhece deriva da vontade dos deuses de serem adorados: "(...) aclare-se o céu e a terra para que sejamos adorados pela manifestação da nossa obra, quando houver gente formada, gente feita" ( $\mathrm{V}, 19)$. No mito Maia, a luz inaugura o universo para os seres humanos poderem existir. Segundo a mitologia Kamaiurá, povo indígena que habita a região do parque do Xingu, a luz do dia não foi um presente, mas uma conquista feita através de um ardil criado pelos irmãos sol e lua (VILLAS BOAS \& VILLAS BOAS, 1970: 92-96). Os mitos relacionados à origem da luz demonstram a importância que este elemento possui para a vida humana e o quanto sua ausência pode ser sentida. De modo geral, nas mitologias, a ausência de luz é encarada como caos, morte e perigo sobrenatural.

Uma das propostas deste ensaio é a de fazer um estudo interdisciplinar da relação dos seres humanos com a luz através da artefatualidade relacionada à iluminação de espaços de convivência. Para isso, investimos num diálogo da arqueologia com a mitologia, a fim de expandir as capacidades interpretativas destes dois ramos do saber. Em termos mais claros, nossa proposta é a de analisar os mitos em seu aspecto artefatual, ao mesmo tempo em que analisamos os artefatos em seu aspecto mitológico. Desta forma, entendemos a cultura material de populações pretéritas como possuidora de algumas características que podem nos proporcionar, a depender dos contextos em que foram encontrados, alguns vislumbres sobre as narrativas míticas que os "potencializavam". De maneira similar, entendemos que as narrativas míticas, mesmo que não mais sendo narradas, podem ter alguns de seus aspectos preservados em artefatos arqueológicos e que, quando analisados de maneira contextual, podem nos proporcionar vislumbres de mitologias antigas.

Outro objetivo deste ensaio é o de fazer uma análise do esforço das sociedades humanas para iluminarem seus espaços de convivência. Desta forma, acreditamos estar trabalhando com o que chamamos de arqueologia temática, que se caracteriza pela 


\section{Revista de Arqueologia Pública}

reflexão a respeito das relações entre os seres humanos, os desafios por eles enfrentados e a cultura material por eles desenvolvida e utilizada para fazer frente a estes desafios, sendo cada um destes desafios considerado um tema. lluminar espaços de convivência é um desafio que vai do desenvolvimento de métodos mais eficientes de manter o fogo acesso durante o paleolítico até o desafio de manter acesas as luzes que iluminam grandes aglomerados urbanos atualmente. Trabalhamos num espectro temporal amplo que se inicia com o domínio do fogo, expresso arqueologicamente através de estruturas de fogueiras encontradas no registro arqueológico, passamos pelo desenvolvimento de instrumentos de iluminação tais como tochas, velas, lâmpadas a óleo, espelhos, lustres, lamparinas, etc., e, por fim, chegamos aos tempos da iluminação pública elétrica.

\section{Brevíssima introdução à arqueologia da luz}

Durante os dias, a humanidade sempre se beneficiou de uma fonte confiável e possante de luz: o sol. Mas, durante as noites, principalmente as de lua nova, a humanidade, durante muitos milênios, precisou se esforçar para manter fontes de luz muito mais fracas e inconfiáveis. Entretanto, o esforço para iluminar seus espaços de convivência fez com que surgisse, a partir do desenvolvimento da iluminação pública em ampla escala, uma situação inédita no planeta. Em muitos lugares, as trevas foram vencidas pelo esforço humano em criar um conjunto artefatual relacionado à iluminação até agora pouco explorado pela arqueologia.

Ainda não existe uma ampla literatura arqueológica enfatizando a luz e o conjunto artefatual relacionado a ela nem suas relações com os aspectos mitológicos que este conjunto artefatual possa conter. No Brasil, quem ousar abordar a luz de maneira arqueológica terá que gastar muita tinta e saliva para provar que ela pode ser tema de pesquisa. Entretanto, algumas publicações começam a clarear um pouco a situação. $O$ Oxford Handbook of Light in Archaeology tem sua publicação prevista para $2015^{2}$. Este manual, editado por Konstantinos Papadopoulos e Graeme Earl, reúne contribuições interdisciplinares que abordam a iluminação de espaços sob um prisma não apenas arqueológico, mas também arquitetônico, antropológico, etc. Konstantinos Papadopoulos e Graeme Earl declaram que começa a haver:

(...) um crescente reconhecimento pelos arqueólogos e antropólogos que as interpretações arqueológicas do espaço, forma e

${ }^{2}$ http://acrg.soton.ac.uk/blog/3672/ 


\section{Revista de Arqueologia Pública}

comportamento estão ausentando a luz como um elemento essencial. Este livro traz novos "dados" ao colocar a luz no centro das narrativas arqueológicas de uma ampla região do mundo e em um amplo espaço de tempo.

O livro irá explorar muitas dimensões da iluminação e escuridão num amplo conjunto de habitações, assentamentos, espaços públicos e privados, monumentos religiosos, assim como em vários aspectos da vida diária no passado e no presente. O livro trará diversos estudos geográficos e cronológicos, indo da pré-história até o presente e da Europa até a América (PAPADOPOULOS e EARL in: http://acrg.soton.ac.uk/blog/3672/3).

Portanto, a luz começa a ser vista como um elemento arqueologicamente perceptível através da cultura material relacionada a ela.

\section{O esforço humano para iluminar seus espaços de convivência}

A conquista do fogo representou muito mais que uma conquista de um poderoso instrumento contra o frio. Ele também foi uma arma poderosa para espantar as feras que ameaçavam a vida humana. A partir do domínio do fogo, também foi possível desenvolver a preparação de alimentos. Submeter os alimentos ao fogo foi uma grande mudança comportamental de amplo impacto social. Contudo, além de calor e capacidade de preparação de alimentos, o domínio do fogo também proporcionou aos grupos humanos do paleolítico um papel preponderante na construção de paisagens. Queimadas naturais sempre existiram, mas com o domínio do fogo pelos seres humanos, o número de queimadas aumentou dramaticamente, gerando com isso grandes modificações nas paisagens. Entretanto, além de modificar a paisagem, o domínio do fogo também a iluminou. A luz é um produto do fogo que não deixa evidências diretas no registro

\footnotetext{
${ }^{3}$ Tradução nossa do trecho original: (...) increasing recognition by archaeologists and anthropologists that archaeological interpretations of space, form and behaviour are missing light as an essential element, this book breaks new ground by placing light at the heart of archaeological narratives from a broad region of the world and a broad sweep of time. It will explore many dimensions of lighting and darkness in a wide range of dwellings, settlements, private and public spaces, monuments and religious buildings, as well as in various aspects of everyday life in the past and the present. The book will bring together diverse geographical and chronological studies, ranging from prehistory to the present and from Europe to America. (PAPADOPOULOS e EARL in.http://acrg.soton.ac.uk/blog/3672/).
} 


\section{Revista de Arqueologia Pública}

arqueológico pré-histórico. Todavia, indiretamente ela é perceptível através de elementos arqueológicos, tais como:

- $\quad$ estruturas de fogueiras

- marcas de combustão em paredes rochosas

- $\quad$ arte rupestre em locais que não recebem luz solar tais como cavernas (zonas afóticas)

As mais antigas evidências do domínio do fogo pelos ancestrais dos seres humanos são datadas de aproximadamente 1.6 milhões de anos atrás ${ }^{4}$. Portanto, o domínio do fogo pode ser muito anterior ao aparecimento do Homo sapiens, que tem cerca de 200.000 anos. Entretanto, apesar da grande antiguidade do possível domínio do fogo e, portanto, o domínio sobre uma fonte de luz, não parece ter existido, durante centenas de milhares de anos, um conjunto artefatual amplo relacionado à iluminação de espaços de convivência. Fogueiras e tochas rudimentares parecem ter servido bem à função de iluminar as noites de milhares de gerações de seres humanos e de seus ancestrais. Contudo, conforme o paleolítico avançava e novas necessidades eram criadas, tais como aquelas relacionadas à feitura de arte rupestre em zonas afóticas, um novo conjunto artefatual relacionado à iluminação precisou ser desenvolvido para atender estas novas necessidades.

A arte rupestre desenvolvida em lugares onde a luz do sol não alcança (zonas afóticas) constitui uma importante evidência indireta do uso da luz pelos grupos paleolíticos. Cavernas tais como as de Lascaux e Altamira são exemplos notáveis do uso da luz e de sua importância social ao permitir que a arte rupestre destas cavernas fosse realizada e admirada. A arte rupestre em zonas afóticas só foi possível porque seus autores possuíam artefatos capazes de manter um nível suficiente de iluminação em ambientes geralmente muito úmidos, como os de cavernas. Tais artefatos que, segundo alguns autores, se constituíam de pedras côncavas preenchidas de gordura representam, talvez, os primeiros exemplares de "lâmpadas" conhecidos (DURANT, 1942: 104).

Aqui se faz necessário o uso de evidências indiretas e imateriais para podermos expandir a interpretação arqueológica sobre o quão socialmente impactante era a atitude de iluminar os interiores profundos de cavernas. As interpretações sobre a arte rupestre e, pode-se dizer, sobre o registro arqueológico em geral, derivam de um amplo leque de perspectivas teóricas que se situam entre um polo "descritivista" e um polo "interpretativista" que se utiliza de doses menores ou maiores de evidências indiretas e imateriais, a fim de

${ }^{4}$ http://archaeology.about.com/od/ancientdailylife/qt/fire control.htm 


\section{Revista de Arqueologia Pública}

realizarem análises verossímeis. Na "hipótese" que apresentaremos sobre o impacto simbólico que o ato de iluminar o interior profundo de uma caverna durante o paleolítico com o objetivo de realizar e admirar o que hoje chamamos de arte rupestre, utilizaremos de uma perspectiva "interpretativista" baseada nos mitos da origem e importância da luz presentes em todas as populações humanas. Em nossa análise, as pessoas encarregadas de levarem luz onde a luz do sol não chega poderiam representar o próprio sol. Elas próprias eram símbolos do sol, personificações da luz que iluminava o mundo para além das cavernas. E estes "sóis" que visitavam as cavernas iluminavam um mundo habitado por imagens de seres que viviam no exterior das cavernas, isto é, o mundo exterior iluminado pelo sol exterior também tinha que ser representado no interior das cavernas para serem iluminados pelo sol interior que cintilava dentro delas. Tal "interpretação" altamente simbólica dos "portadores da luz" não é muito diferente da interpretação que reconhece na hóstia e no vinho das missas católicas o corpo e o sangue de um deus sacrificado para a salvação da humanidade. O elemento "simbólico" substitui o elemento "real" e, como acontece com a hóstia e o vinho segundo a interpretação dos católicos fervorosos, 0 elemento "simbólico" transubstancia-se no elemento "real". A hóstia se torna a carne e o vinho se torna o sangue da divindade imolada. Da mesma maneira, podemos interpretar que a pessoa que adentrava as cavernas portando uma fonte de luz transubstanciava-se em sol e irradiava luz e vida para as imagens pintadas nas paredes rochosas das cavernas.

É claro que a "hipótese" apresentada acima é apenas um exercício intelectual sem uma farta comprovação baseada no registro arqueológico. Em outras palavras, uma conjectura ou uma especulação. E talvez, infelizmente, não tenhamos nenhuma maneira de comprovar isto que poderíamos chamar de "hipótese da descida da divindade solar ao mundo inferior". Entretanto, algo de mais consistente pode ser dito sobre o registro arqueológico direta ou indiretamente relacionado com o esforço para iluminar lugares. É necessário ir além da materialidade do registro e começarmos a pensar numa miticidade deste mesmo registro. Neste sentido, uma simples tocha rudimentar encontrada num sítio cárstico paleolítico, onde condições excepcionais tenham garantido sua "sobrevivência" no registro arqueológico pode representar muito mais que uma tênue fonte de luz, calor, cozimento e proteção, mas o próprio "sol".

A luz emitida pelas fogueiras paleolíticas pode ser vista como um elemento de sociabilidade. A sociabilidade humana pode acontecer mesmo na mais densa das trevas. Entretanto, a luz das fogueiras atua como um elemento a mais de agregação social ao permitir que não apenas as palavras sejam ouvidas, mas também que os gestos e expressões faciais possam ser vistos. Portanto, pode-se dizer que a luz potencializa a 


\section{Revista de Arqueologia Pública}

sociabilidade humana em períodos noturnos. Além disso, simbolicamente, uma fogueira pode ser entendida com um sol noturno, na medida em que ela produz os mesmos efeitos que o sol durante o dia. O calor e a luz de uma fogueira, para um grupo paleolítico, certamente representavam algo muito mais extraordinário do que uma fogueira para os ambientes das iluminadas cidades do século XXI.

Entretanto, não há muitos meios para se aprofundar mais na arqueologia da luz do período paleolítico. Podemos apenas supor sua importância como elemento não apenas relacionado à manutenção das condições "objetivas" da vida, mas também como elemento carregado de miticidade e que, por sua analogia com o sol, poderia ocupar um papel central na constituição e vivência de mitologias e ideologias pretéritas.

$\mathrm{Na}$ antiguidade, diversos instrumentos foram desenvolvidos com o intuito de gerar luz. Lâmpadas a óleo, tochas, castiçais, etc. A importância simbólica da luz neste período pode ser vista através das narrativas mitológicas que enfatizam sua origem divina, tais como as narrativas bíblicas da origem do universo. Um tema muito frequente em diversas mitologias do mundo é o do roubo do fogo por alguma divindade. Um dos exemplos mais famosos destes mitos é o de Prometeu. Sendo a luz um dos principais dons do fogo, podese inferir, através dos mitos do roubo do fogo, a importância conferida pelos povos da antiguidade à iluminação noturna de seus espaços de convívio. Também na antiguidade, foram construídos os faróis para navegação, cujo exemplo mais famoso é o do farol de Alexandria, considerado como uma das sete maravilhas do mundo antigo. Tais faróis utilizavam o fogo como fonte de luz e espelhos para refletir a luz para que ela pudesse ser vista pelos navios que navegavam próximos à costa. $O$ fogo que queimava nos faróis não tinha nenhuma função culinária ou de aquecimento. Sua função única era de produzir luz. Portanto, os faróis da antiguidade podem ser considerados como exemplos de mega artefatos relacionados não apenas à iluminação, mas também a navegação, comércio, rotas marítimas, etc.

Através da antiguidade e da idade média, os artefatos relacionados à luz foram elementos muito utilizados. Velas, tochas, castiçais, lâmpadas a óleo e demais instrumentos iluminaram as noites de centenas de gerações por milênios. A importância da luz na antiguidade pode ser verificada a partir da palavra lar, que, etimologicamente, está relacionada à palavra lareira, significando assim o fogo residencial em torno do qual se dava a sociabilidade noturna. Portanto, o conjunto artefatual relacionado à luz na antiguidade constitui um importante elemento que pode ser estudado arqueologicamente através de diversas abordagens teóricas. 


\section{Revista de Arqueologia Pública}

$\mathrm{Na}$ idade média, as igrejas eram os espaços iluminados por excelência. Lustres, candelabros, lâmpadas a óleo, tochas, velas, etc., iluminavam os espaços internos das igrejas. Entretanto, um elemento de forte impacto simbólico usado pelas igrejas não era diretamente relacionado com a produção de luz, mas se utilizava da luz solar para aumentar seu impacto simbólico. Os vitrais podem ser entendidos como artefatos de forte cunho simbólico (um arqueólogo processualista poderia classificá-los como artefatos ideotécnicos). Embora eles não produzam luz, a "filtragem" da luz solar que recebem faz com que as imagens religiosas representadas neles adquiram um efeito simbólico mais expressivo, constituindo assim elementos artefatuais relacionados com a manutenção do poder religioso na idade média.

O desenvolvimento urbanístico de algumas cidades levou à necessidade de se aprimorar os instrumentos de iluminação, a fim de se poder iluminar uma maior quantidade de espaços públicos. A iluminação pública, por exemplo, foi mantida em algumas cidades do século XIX através do uso de óleo de baleia, gerando com isso uma enorme caça a esses animais, quase levando-os à extinção. A caça à baleia com propósitos de captação de óleo para iluminação só foi terminar no final do século XIX, com o uso crescente da querosene a base de petróleo. Entretanto, a crescente demanda de iluminação dos espaços urbanos do século XIX representou o surgimento do perigo de extinção para esses animais que nunca antes tiveram que enfrentar tão terrível ameaça.

Em fins do século XIX, aconteceu um evento revolucionário que mudou as relações sociais. A invenção da lâmpada elétrica incandescente por Thomas Edson. A luz elétrica e sua rápida expansão a partir do século XIX gerou a necessidade de se criar uma infraestrutura capaz de gerar eletricidade para milhões de pessoas. Também no final do século XIX, foram criadas as primeiras hidrelétricas de pequeno porte ${ }^{5}$. Com o objetivo de dar suporte à expansão da eletricidade, por todo o mundo foram criadas barragens para geração de energia hidrelétrica. As hidrelétricas são grandes estruturas que, construídas em cursos de rios, causam grandes impactos ambientais que afetam não apenas os animais, mas também as sociedades humanas, tais como povos indígenas que veem seus territórios tomados pelos lagos formados pelas barragens.

As hidrelétricas e termoelétricas constituem mega artefatos relacionados com a eletricidade e, por este motivo, estão relacionados com a iluminação pública. As linhas de transmissão que conduzem a eletricidade para as áreas urbanas e rurais constituem enormes conjuntos artefatuais que só podem ser entendidos quando relacionados com as

${ }^{5}$ http://www.planetseed.com/pt-br/relatedarticle/fontes-alternativas-de-energia-energia-hidreletrica 


\section{Revista de Arqueologia Pública}

demandas sociais por energia elétrica, sobretudo para iluminação, que se avolumam no decorrer do século XX.

Os espaços urbanos atuais são enormes concentrações de cultura material produzida, em grande medida, usando energia elétrica, e no exercício de produzir esse imenso volume de cultura material, a luz é um elemento de vital importância, pois, através dela, abriu-se a possibilidade de trabalho noturno. As atividades humanas no período noturno foram amplamente alargadas e potencializadas com o desenvolvimento dos métodos, meios e artefatos relacionados à iluminação. Não há meios de sabermos quais atividades os seres humanos do paleolítico exerciam durante a noite. Provavelmente atividades relacionadas à contação de narrativas míticas, rituais ou mesmo conversas habituais. Podemos conjecturar que antes do domínio do fogo, as atividades noturnas dos grupos pré-humanos do paleolítico eram muito restritas, principalmente nas noites de lua nova. Num cenário de escuridão total, mesmo a luz de uma pequena chama pode exercer uma forte atração social e possibilitar um grande aumento de atividades exercidas.

Outro fator que precisa ser observado é que, a partir da iluminação pública em larga escala, em inícios do século XX, houve um grande número de transformações de paisagens. Várias cidades de todo o mundo passaram a contar com sistemas de iluminação pública, o que possibilitou um incremento da "vida noturna", afetando as relações humanas que não mais ficaram tão dependentes da luz solar.

Um aspecto importante é que, conforme Gosden,

ao ollhar para o ambiente construído uma pessoa pode facilmente ver os tipos de obrigações que as coisas colocam sobre as pessoas ao criarem ambientes nos quais crianças nascem e se socializam, internalizando um conjunto de regras espaciais e sociais nas quais 0 poder se encontra no fato de que elas são inconscientemente obedecidas mais que formalmente ensinadas ${ }^{6}$ (GOSDEN, 2005: 202).

Pode-se dizer que a iluminação pública em larga escala, ao criar ambientes intensamente iluminados, gerou um conjunto de regras sociais e espaciais que levou a modificações comportamentais de grandes proporções em bilhões de pessoas em todo 0 mundo que vivem em áreas urbanas ou em áreas rurais, onde a luz elétrica se faça

\footnotetext{
${ }^{6}$ In looking at the built environment one can easily see the sorts of obligations things placed upon people, creating environments into which children were born and socialized, internalizing a set of spatial and social rules, whose power lay in the fact that they were unconsciously obeyed, rather than being formally taught.
} 


\section{Revista de Arqueologia Pública}

presente. As cidades, espaços iluminados por excelência, geraram uma forte atração sobre bilhões de pessoas. Hoje, possivelmente pela primeira vez na história mundial, a população urbana supere a população rural em várias partes do mundo, tais como a Europa ocidental, a América do Norte e, inclusive, alguns lugares da América do Sul tais como o Brasil, onde, segundo dados do IBGE do censo de 2010, aproximadamente $84,5 \%$ da população vive em áreas urbanas. O acesso mais fácil à luz elétrica nos espaços urbanos constitui um dos fatores deste fluxo migratório em direção às cidades.

Com o crescente domínio das técnicas de iluminação, o comportamento das pessoas beneficiadas pela luz alterou-se significativamente. Numa cidade grande atualmente, já é possível a uma pessoa trocar o dia pela noite. A iluminação pública desenvolveu a necessidade de expansão das jornadas de trabalho até o período noturno. $O$ crescente número de estabelecimentos comerciais que funcionam 24 horas fez aumentar o número de trabalhadores do período noturno. Estes trabalhadores, pode-se dizer, tiveram que trocar o dia pela noite.

O esforço humano para iluminar seus espaços de convivência levou a uma situação inédita no planeta. Pela primeira vez, a luz se tornou, em alguns pontos do planeta, excessiva, gerando uma situação em que, em alguns casos, a escuridão passou a ser um bem escasso. A luz, em algumas localidades, tornou-se poluição visual. A situação é mais dramática para algumas espécies animais, tais como as tartarugas marinhas, que depositam seus ovos em praias. Conforme os seres humanos ocupam os espaços litorâneos, construindo prédios nas proximidades das praias e, com isso, iluminando estes espaços, perturbando a desova das tartarugas marinhas, atrapalhando, assim, o processo de reprodução da espécie.

\section{A luz à luz de diferentes teorias arqueológicas}

Com o intuito de iluminar seus espaços de convivência, as diferentes sociedades se utilizaram de conjuntos artefatuais que, direta ou indiretamente, estão relacionados com a produção de luz. Enquanto algumas sociedades, tais como aquelas do paleolítico, parecem não ter desenvolvido um amplo conjunto artefatual, ficando restritas às fogueiras, tochas e, talvez, "lâmpadas" de sebo, outras sociedades, tais como as sociedades globalizadas do século XXI, desenvolveram um conjunto que pode ser considerado não apenas como artefatual, mas também "mega-artefatual". Para que as lâmpadas fluorescentes e incandescentes que iluminam milhões de lares por todo o mundo possam funcionar, mega-artefatos, tais como as torres de transmissão de energia elétrica, centrais 


\section{Revista de Arqueologia Pública}

elétricas, hidrelétricas, termoelétricas e usinas nucleares são necessárias. Com isso em mente, podemos desenvolver uma tabela, na qualtentamos demonstrar como cada teoria arqueológica estudaria a questão da luz nas diferentes sociedades.

\begin{tabular}{|c|c|}
\hline Teoria & Posicionamento \\
\hline Histórico Culturalismo & $\begin{array}{l}\text { Alguns artefatos relacionados à iluminação, } \\
\text { tais como lâmpadas à óleo, podem ter } \\
\text { elementos, tais como o estilo, que permitam } \\
\text { estabelecer algumas características } \\
\text { relacionadas a identidades étnicas. O } \\
\text { candelabro menorá, por exemplo, funcionou } \\
\text { como marcador étnico entre os hebreus e } \\
\text { judeus. }\end{array}$ \\
\hline Processualimo Funcionalista & $\begin{array}{l}\text { As tecnologias de iluminação podem ser } \\
\text { entendidas como tecnofatos relacionados à } \\
\text { adaptação dos povos aos ambientes que } \\
\text { habitavam. Desta forma, povos com } \\
\text { tecnologias de iluminação mais } \\
\text { desenvolvidas teriam um nível maior de } \\
\text { adaptação aos ambientes em que viviam. A } \\
\text { luz pode ser entendida como um recurso } \\
\text { natural cuja obtenção deixa vestígios } \\
\text { arqueológicos (estruturas de fogueiras, } \\
\text { tochas, arte rupestre em zonas afóticas, } \\
\text { lâmpadas à óleo, castiçais, etc). Tais } \\
\text { vestígios arqueológicos revelam diferentes } \\
\text { graus de desenvolvimento tecnológico e } \\
\text { adaptação ao ambiente. A luz também pode } \\
\text { ser entendida como elemento simbólico } \\
\text { ligado a concepções religiosas e, portanto, } \\
\text { intimamente relacionadas a questões } \\
\text { ideológicas, gerando assim artefatos } \\
\text { ideotécnicos. }\end{array}$ \\
\hline Pós-processualismo & $\begin{array}{l}\text { Os artefatos relacionados à iluminação não } \\
\text { apenas respondem às necessidades de } \\
\text { adaptação das sociedades aos ambientes } \\
\text { em que vivem. Alguns elementos artefatuais } \\
\text { relacionados com a luz possuem significados }\end{array}$ \\
\hline
\end{tabular}




\begin{tabular}{|c|c|}
\hline & $\begin{array}{l}\text { simbólicos que expressam um amplo leque } \\
\text { de representações que não apenas possuem } \\
\text { natureza religiosa, mas que também indicam } \\
\text { questões relacionadas a desigualdade social } \\
\text { (relação entre espaços mais e menos } \\
\text { iluminados); ideológicas (o uso de artefatos } \\
\text { de iluminação tais como espelhos em } \\
\text { cerimônias), etc. É importante observar cada } \\
\text { contexto em que a iluminação teria sido } \\
\text { usada. Em alguns contextos, a ausência } \\
\text { completa de iluminação poderia estar ligada } \\
\text { a aspectos de iniciação religiosa } \\
\text { relacionadas com a morte. Em outros } \\
\text { contextos, a intensidade da iluminação } \\
\text { poderia estar ligada a cerimônias políticas e } \\
\text { religiosas de fortalecimento das classes } \\
\text { dominantes. O papel da luz em templos, } \\
\text { palácios e demais espaços cerimoniais deve } \\
\text { ser levado em consideração em cada } \\
\text { contexto investigado. }\end{array}$ \\
\hline Arqueomitologia & $\begin{array}{l}\text { Os artefatos relacionados à iluminação de } \\
\text { espaços de convivência podem representar } \\
\text { muito mais que apenas artefatos funcionais } \\
\text { de uso cotidiano, mas artefatos carregados } \\
\text { de uma intensa carga mítica a ser verificada } \\
\text { através dos contextos em que foram } \\
\text { encontrados. Numa pesquisa } \\
\text { arqueomitológica, tal classe artefatual } \\
\text { poderia ser abordada como o "eco" material } \\
\text { de narrativas míticas pretéritas relacionadas } \\
\text { a aspectos da existência tais como vida, ritos } \\
\text { iniciáticos e morte. O contexto onde os } \\
\text { artefatos de iluminação eram utilizados } \\
\text { fornecem pistas para sua interpretação. } \\
\text { Assim, artefatos de tal classe encontrados } \\
\text { em enxoval funerário sugerem uma mitologia } \\
\text { onde a luz exercia um papel fundamental } \\
\text { para o "bem-estar" dos mortos. }\end{array}$ \\
\hline
\end{tabular}




\section{Revista de Arqueologia Pública}

Tabela de posicionamentos teóricos em relação à luz. Autor: Orestes Jayme Mega (2015)

Charles E. Orser, um dos mais influentes arqueólogos históricos da atualidade apresentou, em seu artigo intitulado The Archaeology of Poverty and the Poverty of Archaeology uma definição de pobreza e de como ela poderia ser verificada arqueologicamente: "At its core, poverty is the physical appearance of social inequality, exclusion, and the unequal distribuition of wealth" (2011: 538). Poderíamos acrescentar logo ao final da definição de Orser as palavras and light. Luz e riqueza costumam andar juntas, podendo esta relação ser observada arqueologicamente, pois os espaços de convivência dos afortunados são melhor iluminados. Aos pobres sobram os espaços mal iluminados, onde a noite é mais escura e a escuridão mais feroz. Lustres, candelabros, vitrais, lâmpadas a óleo e elétricas são artefatos que podem servir de indicativos de riqueza e posição social. Diferenças de estilo nesta classe de artefatos podem ser usadas para indicar o grau de desigualdade social presente em uma sociedade.

Gosden enfatiza o poder de agência dos objetos e como os objetos usam os seres humanos para se multiplicarem:

Ao canalizar e constranger as ações humanas um tipo pode ajudar a trazer outros à existência. Então alguns elementos do mundo dos objetos ajudam outros a virem a existir. Os objetos usam os músculos e as habilidades humanas para fazer a sua própria reprodução. De modo similar, populações de artefatos "exibirão suas características comportamentais específicas às quais são mais complexas que o simples conjunto de características dos componentes e mais predizíveis que a dos componentes individuais (CLARKE, 1978: 150 apud GOSDEN, 2005: 194)7

Além dos objetos usarem os músculos humanos para fazerem outros objetos surgirem, podemos afirmar que os objetos usam os olhos humanos com o mesmo propósito. Com a crescente eficácia dos instrumentos de iluminação, uma quantidade muito maior de objetos puderam ver a luz que, iluminando os espaços de produção, multiplicaram a produtividade de outros objetos.

\footnotetext{
7 Tradução nossa do trecho original: By channeling and constraining human actions one type can help bring others into being, so that some elements of the object world help bring others into being. Objects use human muscles and skills to bring about their own reproduction. Similarly, populations of artifacts will "exhibit their own specific 'behavioural' characteristics which are more complex than the simple sum of the characteristics of the components and more predictable than that of the individual components". (CLARKE, 1978: 150 apud GOSDEN, 2005: 194).
} 


\section{Revista de Arqueologia Pública}

\section{As paisagens iluminadas do antropoceno}

O esforço humano para iluminar seus espaços de convivência culminou na criação de paisagens densamente iluminadas. Tais paisagens podem ser facilmente reconhecidas através de fotos noturnas do planeta tiradas do espaço. Estas fotos revelam que a escuridão da noite está se tornando um elemento cada vez mais raro no planeta. Em alguns lugares, tais como a Europa ocidental e o Leste da América do norte, a intensidade da iluminação pública revela-se como uma miríade de pontos luminosos. Estes pontos, muito próximos uns dos outros, podem ser entendidos como manchas luminosas que, rapidamente, crescem e multiplicam-se, gerando em seu crescimento uma espécie de "photosfera" (esfera de luz). Se atentarmos para a rapidez com que a iluminação pública de larga escala se expandiu pelo mundo durante o século $X X$ e princípios do $X X I$, veremos que, em não muito tempo, surjam grupos organizados de proteção dos "lugares escuros". A luz, em alguns casos, tornou-se excessiva num mundo que há não muito tempo temia a escuridão que o envolvia todas as noites.

Podemos denominar o século XX de diversas formas. Erich Hobsbawn, famoso historiador inglês, denominou o século $X X$ de a Era dos Extremos. Outra denominação que pode ser aplicada ao século XX é a de o século da cruzada contra as trevas. Em questão de décadas, o planeta assistiu a uma de suas mais extraordinárias transformações em sua superfície. De um planeta divido entre uma parcela iluminada e uma parcela escura, hoje pode-se dizer que o planeta tem uma parcela iluminada pela luz do sol e uma parcela iluminada pela luz do esforço humano. Esta é uma das características mais impressionantes de uma era que começa a ser chamada de Antropoceno e que se caracteriza pelas impressionantes marcas do esforço humano que, em alguns lugares, tais como nos países altamente industrializados, tem exercido um poder semelhante às das grandes forças geológicas que modelam o relevo do planeta (STEFFEN, CRUTZEN, MCNEILL, 2007).

As crescentes manchas luminosas que se espalham pelo planeta demarcam muito mais que apenas espaços iluminados. Elas demarcam espaços altamente transformados, espaços antropizados e plenos de cultura material sendo produzida, consumida e descartada. Acreditamos que a arqueologia tem muito a ganhar ao adentrar nestes espaços iluminados e esclarecer ainda mais a longa marcha do esforço humano em sua cruzada contra as trevas. 


\section{Revista de Arqueologia Pública}

\section{Referências bibliográficas}

BÍBLIA ONLINE. Disponível em: https://www.bibliaonline.com.br/acf/gn/1. Acesso em: 10/08/2014.

DURANT. W. História da Civilização, Tomo I. Companhia editora nacional. São Paulo, 1942.

GOSDEN. C. What Do Objects Want? In: Journal of Archaeological Method and Theory. Volume 12. Número 3. Springer, 2005.

HIRST. K. The Discovery of Fire - Two Million Years of Campfire Stories. Disponível em: http://archaeology.about.com/od/ancientdailylife/qt/fire control.htm. Acesso em: 09/08/2014.

ORSER. C. E. The Archaeology of Poverty and the Poverty of Archaeology. In: International journal of Historical Archaeology, Volume 15, número 4. Springer, 2011.

PAPADODOPOULOS K. GRAEME E. The Oxford Handbook of Light in Archaeology. Disponível em: http://acrg.soton.ac.uk/blog/3672/. Acesso em: 09/08/2014.

POPOL - VUH. El libro del consejo de los índios Quichés. Disponível em: http://www.samaelgnosis.net/sagrados/pdf/popol vuh.pdf. Acesso em: 12/08/2014.

SEED CIÊNCIAS. Fontes Alternativas de Energia: Energia Hidrelétrica. Disponível em: http://www.planetseed.com/pt-br/relatedarticle/fontes-alternativas-de-energia-energiahidreletrica. Acesso em: 09/08/2014.

STEFFEN, W.; CRUTZEN, P.; MCNEILL, J: "The Anthropecene: are humans now overwhelming the great forces of nature?" Ambio. Vol. 36. Número 8. Páginas $614-621$. Dez. 2007. Disponível em: http://ambio.kva.se. Acesso em 11/08/2014.

VILLAS BOAS, O. \& VILLAS BOAS, C. Xingu: Os Índios, Seus Mitos. Ed. Edibolso. São Paulo. 1970. 